\title{
Efficacy of Chlorhexidine, Polihexanide and Tissue-Tolerable Plasma against Pseudomonas aeruginosa Biofilms Grown on Polystyrene and Silicone Materials
}

\author{
N.-O. Hübner ${ }^{a} \quad$ R. Matthes ${ }^{a} \quad$ I. Koban ${ }^{b} \quad$ C. Rändler ${ }^{a} \quad$ G. Müller ${ }^{a} \quad$ C. Bender ${ }^{a}$ \\ E. Kindel ${ }^{\mathrm{c}}$ T. Kocher ${ }^{\mathrm{b}} \quad$ A. Kramer ${ }^{\mathrm{a}}$ \\ ${ }^{\mathrm{a}}$ Institute of Hygiene and Environmental Medicine, and ${ }^{\mathrm{b}}$ Centre for Dental and Oral Medicine and Maxillofacial \\ Surgery, Ernst Moritz Arndt University Greifswald, and ' Leibniz Institute for Plasma Research and Technology, \\ Greifswald, Germany
}

\section{Key Words}

Chlorhexidine $\cdot$ Polihexanide $\cdot$ Pseudomonas aeruginosa .

Biofilm efficacy $\cdot$ Tissue-tolerable plasma

\begin{abstract}
Background: The formation of biofilms is crucial in the pathogenesis of many acute and subacute microbial infections, including chronic wounds and foreign-body-related infections. Topical antimicrobial therapy with chemical antiseptics or physical treatment with tissue-tolerable plasma (TTP) may be promising to control bacterial infection. Methods: We assessed the efficacy of $0.1 \%$ chlorhexidine digluconate $(\mathrm{CHX}), 0.02$ and $0.04 \%$ polihexanide (polyhexamethylene biguanide, PHMB) and of TTP against Pseudomonas aeruginosa SG81 biofilm grown in microtitre plates (polystyrene) and on silicone materials in an artificial wound fluid. Results: Overall, PHMB was as effective as $\mathrm{CHX}$ in reducing the total amount of biofilm (gentian violet assay) and in reducing the bacterial metabolism in biofilms (XTT assay). TTP also led to a significant reduction in colony-forming units. Conclusion: The antimicrobial activity of PHMB in biofilms is comparable to that of CHX. TTP could become an interesting physical alternative to chemical antisepsis in the future.
\end{abstract}

Copyright ๑ 2010 S. Karger AG, Basel

\section{Introduction}

The formation of biofilms is crucial in the pathogenesis of many acute and subacute microbial infections, including chronic wounds and foreign-body-related infections $[1,2]$. Bacteria organized in biofilms are distinctly less susceptible to host defences and antimicrobial therapy compared with their planktonic counterparts [3-5]. Topical antimicrobial therapy with antiseptics or with tissue-tolerable plasma (TTP) could be an interesting option for biofilm elimination, given that these measures are effective in the inactivation and removal of microbial biofilms, but data available on this topic are limited.

We therefore compared the efficacy of chlorhexidine digluconate (CHX) with that of polihexanide (polyhexamethylene biguanide, PHMB) and TTP against Pseudomonas aeruginosa grown in microtitre plates and on silicone in vitro with different analytic methods.

Chlorhexidine is one of the most frequently used antiseptics worldwide, the gold standard for oral cavity antisepsis, and effective against developing and mature biofilms [6-10]. As the microbicidal efficacy of polihexanide is comparable to that of chlorhexidine [11], but PHMB, despite structural similarity, differs from chlorhexidine in that it does not contain the toxicologically critical ter-

\section{KARGER}

Fax +4161306 1234

E-Mail karger@karger.ch

www.karger.com
(C) 2010 S. Karger AG, Basel

$1660-5527 / 10 / 0237-0028 \$ 26.00 / 0$

Accessible online at:

www.karger.com/spp
Nils-Olaf Hübner, MD

Institute of Hygiene and Environmental Medicine

Ernst Moritz Arndt University Greifswald, Walther Rathenau Strasse 49a DE-17489 Greifswald (Germany)

Tel. +49 383451 5546, Fax +49383451 5541, E-Mail nhuebner@uni-greifswald.de 
minal chlorobenzene substituents, it was to be compared with chlorhexidine in its effect against biofilms. A further reason for the choice of polihexanide is its growing importance as an antiseptic substance and its related increasing use, particularly for the treatment of infected wounds and for decolonization of skin [Hübner and Kramer, this supplement issue; 12-14], as well as for the decolonization of mucous membranes of patients colonized with methicillin-resistant Staphylococcus aureus [Eberlein and Assadian, this supplement issue].

The use of TTP as a physical alternative to chemical antisepsis appears promising, because plasma, too, depending on the dose, is microbicidally effective $[15,16]$ and in the body temperature range can also be used on the surface of the body [17]. Unlike chemical antisepsis, energy can be supplied to the wound tissue through the use of plasma, thus possibly contributing to promoting the healing process. The possibility of the use of TTP worldwide is therefore being studied in centres specializing in this.

\section{Materials and Methods}

\section{Bacterial Strains and Growth Conditions}

The bacterium used in this study was a mucoid environmental $P$. aeruginosa strain SG81 which was isolated from a biofilm in a technical water system and was provided by the biofilm centre Duisburg, Germany. This strain is a well-characterized and stable alginate-producing strain that forms highly mucoid colonies on standard media agar. The content of the alginate was subclassified in mannose and glucose residues in which the mannose residues outweigh with $67 \%[18,19]$. The bacteria were grown overnight on Columbia blood agar at $37^{\circ} \mathrm{C}$ for $24 \mathrm{~h}$. A single colony was then transferred to trypticase soy agar plates (Oxoid, Cambridge, UK) and was incubated for $24 \mathrm{~h}$ at $37^{\circ} \mathrm{C}$. The grown cells were suspended in phosphate-buffered saline (PBS), harvested by centrifugation for $15 \mathrm{~min}$ at $3,000 \mathrm{~g}$, washed twice in PBS and resuspended in artificial wound fluid (minimal essential medium + $10 \%$ fetal bovine serum) (GIBCO-Invitrogen, Karlsruhe, Germany) $[11]$ to a final concentration of approximately $1 \times 10^{9}$ colonyforming units $(\mathrm{CFU}) / \mathrm{ml}$.

Culture of the Biofilms and Preparation of the Samples

Biofilms were cultured on test objects made of silicone with a diameter of $0.6 \mathrm{~cm}$ (Thomasil-60, Reichelt Chemietechnik, Heidelberg, Germany) and in the wells of cell culture 24-well microtitre plates (Techno Plastic Products AG, Switzerland).

The final bacteria medium consisted of the artificial wound and the washed bacteria at a final concentration of $10^{8} \mathrm{CFU} / \mathrm{ml}$. The sterile test objects were positioned in 24-well microtitre plates, covered with $0.7 \mathrm{ml}$ microorganism suspension, and incubated aerobically on the agitator (Polymax, Heidolph, Germany) at $160 \mathrm{rpm}$ for $4 \mathrm{~h}$ at $37^{\circ} \mathrm{C}$. For the direct culture, on 96-well microtitre plates, $50 \mu \mathrm{l}$ microorganism suspension per well was applied by pipette and likewise incubated. After $4 \mathrm{~h}$, the suspension was drawn off and replaced by sterile medium; after renewed in-

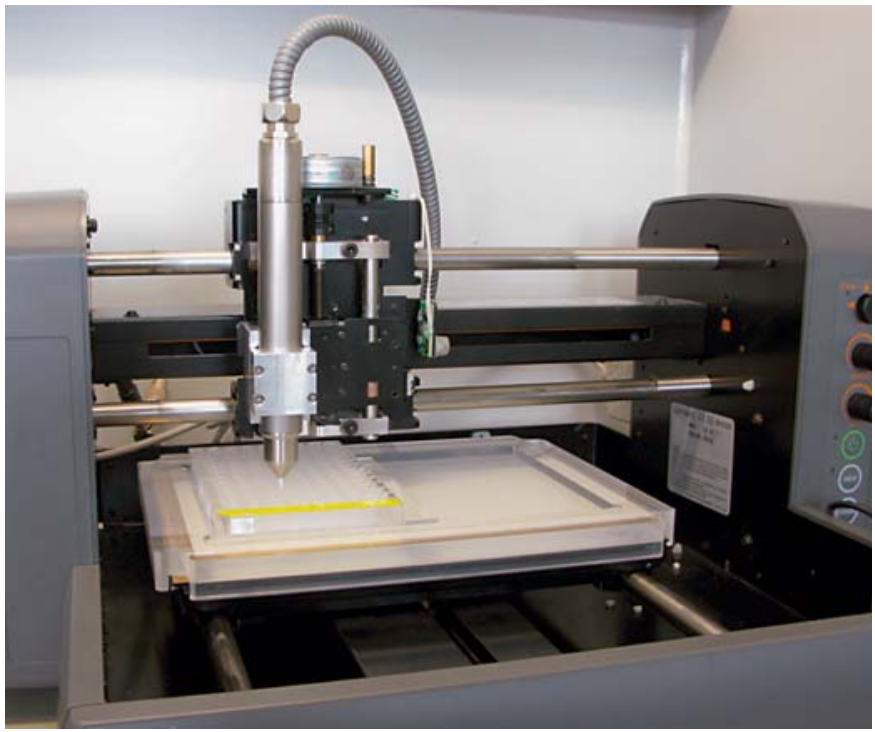

Fig. 1. Configuration for plasma treatment. The KINPen 09 is attached to the $\mathrm{x} / \mathrm{y} / \mathrm{z}$-plotting table. The microtitre plate is fixed. Movement of the pen is controlled by a PC (not shown).

cubation, the medium was changed every $8 \mathrm{~h}$. After $44 \mathrm{~h}$, the medium was drawn off and the test object/well was washed with PBS.

\section{Test Substances and Antiseptic Treatment}

$\mathrm{CHX}$ was used as a $0.1 \%$ aqueous solution (production by the pharmacy of Greifswald University Hospital). For production of the PHMB solutions, Cosmocil, a 20\% PHMB solution (Arch Biocides, UK) was used.

The test objects were transferred into new, sterile microtitre plates, covered with $0.9 \mathrm{ml}$ of the antiseptic, and incubated. After $30 \mathrm{~min}$, the antiseptic was drawn off, and the antiseptic effect was halted by adding $1 \mathrm{ml}$ inactivator (see below). In the case of the 96-well microtitre plates, $90 \mu \mathrm{l}$ antiseptic was added, and the effect halted with $100 \mu \mathrm{l}$ inactivator. PBS was used as the control.

Both antiseptics were inactivated using $40 \mathrm{~g} / \mathrm{l}$ Tween $80,30 \mathrm{~g} / \mathrm{l}$ saponin, $4 \mathrm{~g} / \mathrm{l}$ lecithin, $10 \mathrm{~g} / \mathrm{l} \mathrm{SDS}$ and $1 \mathrm{~g} / \mathrm{l}$ sodium thioglycolate. The inactivation of the antiseptics by the inactivator was proved in the quantitative suspension test according to DIN 1040 (data not shown).

\section{Treatment with TTP}

As the plasma source, an HF plasma pen (frequency $1.82 \mathrm{MHz}$, input power $3 \mathrm{~W}$; KINPen 09, INP Greifswald; fig. 1) was used with argon as the carrier gas $[20,21]$. During treatment, the plasma generated in the jet (spatial afterglow plasma, effluent) is directed to the treated surface at an argon flow rate of 5 standard $1 / \mathrm{min}$, the temperature at the plasma tip being $42{ }^{\circ} \mathrm{C}$. At this temperature, a mean heat output of about $150 \mathrm{~mW}$ is generated on the surface.

For plasma use, the plasma source was attached to a computercontrolled $\mathrm{x} / \mathrm{y} / \mathrm{z}$ table and the test object or microtitre plate was positioned below it (fig. 1). The distance from the test object or bottom of the microtitre plate was $7 \mathrm{~mm}$. The entire surface of the 
Table 1. Effect of CHX, PHMB and non-thermal plasma on biofilms in microtitre plates (mean \pm SD)

\begin{tabular}{|c|c|c|c|c|c|c|}
\hline $\begin{array}{l}\text { 96-well micro- } \\
\text { titre plate }\end{array}$ & PBS & CHX 0.1\% & РНMB 0.02\% & РНMB 0.04\% & TTP & Gas \\
\hline GV & $0.0704 \pm 0.0801$ & $0.0196 \pm 0.0441$ & $0.0284 \pm 0.0350$ & $0.0374 \pm 0.0659$ & $0.0048 \pm 0.0116$ & $0.0118 \pm 0.0122$ \\
\hline XTT & $0.0625 \pm 0.0191$ & $0.0093 \pm 0.0100^{1}$ & $0.0226 \pm 0.0055^{1}$ & $0.0194 \pm 0.0064^{1}$ & $0.0602 \pm 0.0320$ & $0.0780 \pm 0.0063$ \\
\hline CFU & $7.13 \pm 0.65$ & $5.87 \pm 0.60^{1}$ & $6.71 \pm 0.64^{2}$ & $5.77 \pm 0.45^{1}$ & $4.02 \pm 0.33^{1,2}$ & $4.88 \pm 1.00^{1}$ \\
\hline
\end{tabular}

${ }^{1}$ Significant difference from PBS.

2 Significant difference from CHX.

Table 2. Effect of CHX, PHMB and non-thermal plasma on biofilms on silicone swatches (mean \pm SD)

\begin{tabular}{lcccccc}
\hline Silicone & PBS & CHX 0.1\% & PHMB 0.02\% & PHMB 0.04\% & TTP & Gas \\
\hline GV & $0.0020 \pm 0.0356$ & $-0.0107 \pm 0.0333$ & $0.0070 \pm 0.0188$ & $-0.0215 \pm 0.0338$ & $0.1545 \pm 0.0932^{1,2}$ & $0.1168 \pm 0.1475^{1,2}$ \\
XTT & $0.067 \pm 0.052$ & $0.022 \pm 0.021$ & $0.053 \pm 0.071$ & $0.017 \pm 0.033^{1}$ & $0.085 \pm 0.027^{2}$ & $0.126 \pm 0.035^{1,2}$ \\
CFU & $7.31 \pm 0.16$ & $2.83 \pm 3.13^{1}$ & $4.05 \pm 3.15^{1}$ & $5.15 \pm 2.64^{1}$ & $3.84 \pm 0.78^{1}$ & $6.39 \pm 0.33^{1,2}$ \\
\hline
\end{tabular}

${ }^{1}$ Significant difference from PBS.

${ }^{2}$ Significant difference from CHX.

test object was treated meander-like at a speed of $10 \mathrm{~mm} / \mathrm{s}$. The whole time of treatment was $60 \mathrm{~s}$. The samples were also treated with inactivation solution to destroy possible existing radicals.

\section{Determination of the $C F U$}

After $5 \mathrm{~min}$ of inactivation, biofilms were detached in $5 \mathrm{ml}$ PBS using sonication for $20 \mathrm{~min}$ at $130 \mathrm{~W}$. CFU were determined by serial dilutions, which were plated on trypticase soy agar and incubated for $24 \mathrm{~h}$ at $37^{\circ} \mathrm{C}$.

\section{Determination of the Biofilm Mass Using Gentian Violet}

Assay

The evaluation was carried out according to published methods [22-24]. After $5 \mathrm{~min}$ of inactivation, the inactivator was drawn off, the objects were rinsed with fresh PBS and dried for at least $60 \mathrm{~min}$ at $37^{\circ} \mathrm{C}$. The samples were then covered with $0.1 \%$ gentian violet $(\mathrm{GV})$, incubated for $15 \mathrm{~min}$, washed three times with distilled water, and then decoloured with $96 \% \mathrm{v} / \mathrm{v}$ ethanol $\mathrm{HCl}$ (Merck, Darmstadt, Germany). The supernatant was pipetted off and the extinction detected in the photometer at $590 \mathrm{~nm}$ (BIO-TEK, Power Wave XS).

\section{Determination of Vitality Using XTT}

For this, a procedure optimized for $P$. aeruginosa on the basis of the literature was used [25-27]. After 5 min of inactivation, the inactivator was drawn off and fresh PBS was added. To each of the samples, $250 \mu \mathrm{l}$ of the stain solution, consisting of a mixture of sodium 3'-[1-(phenylaminocarbonyl)-3,4-tetrazolium]-bis(4methoxy-6-nitro) benzene sulphonic acid hydrate (XTT; 180 mg/l; AppliChem, Darmstadt, Germany), menadione (0.688 mg/l; Sigma-Aldrich, Munich, Germany) and N-methylphenazinium methyl sulphate $(20 \mathrm{mg} / \mathrm{l}$; AppliChem) in distilled water, were added and incubated for $3 \mathrm{~h}$ at $37^{\circ} \mathrm{C} ; 200 \mu \mathrm{l}$ were transferred to a new sterile microtitre plate and evaluated in the photometer at $450 \mathrm{~nm}$ (reference value $620 \mathrm{~nm}$ ).

\section{Confocal Laser Scanning Microscopy}

Two different dyes, Live/Dead (BacLight, Invitrogen, Darmstadt, Germany, SKU\# L-7012) and acridine orange (AppliChemBioChemica, Darmstadt, Germany), were used to visualize the components of the biofilm. The samples were transferred into a 24-well microtitre plate and incubated immediately according to the manufacturer's instructions. After incubation and fixation, samples were rinsed 5 times with PBS to remove dye residues. Samples were then placed onto glass object slides covered with 10 $\mu l$ Mowiol 4-88 (Polysciences Inc., Eppelheim, Germany) and a coverslip placed on top. Samples were observed using a Zeiss CLSM510 Exciter confocal laser scanning microscope with a 488$\mathrm{nm}$ argon laser. Microscope work was carried out using the oil immersion Plan-Neofluar 63×/1.4 Oil DIC objective.

\section{Biostatistics}

All tests were carried out sixfold each for the CFU, biofilm mass determinations, and in duplicate for the staining. In addition, for each test, 6 samples were used as controls. The Friedman test was used for testing for global statistical differences in microorganism count, biofilm mass and vitality, and if the result was significant, further testing was carried out with the Wilcoxon test. The level of significance was set at 0.05 . 

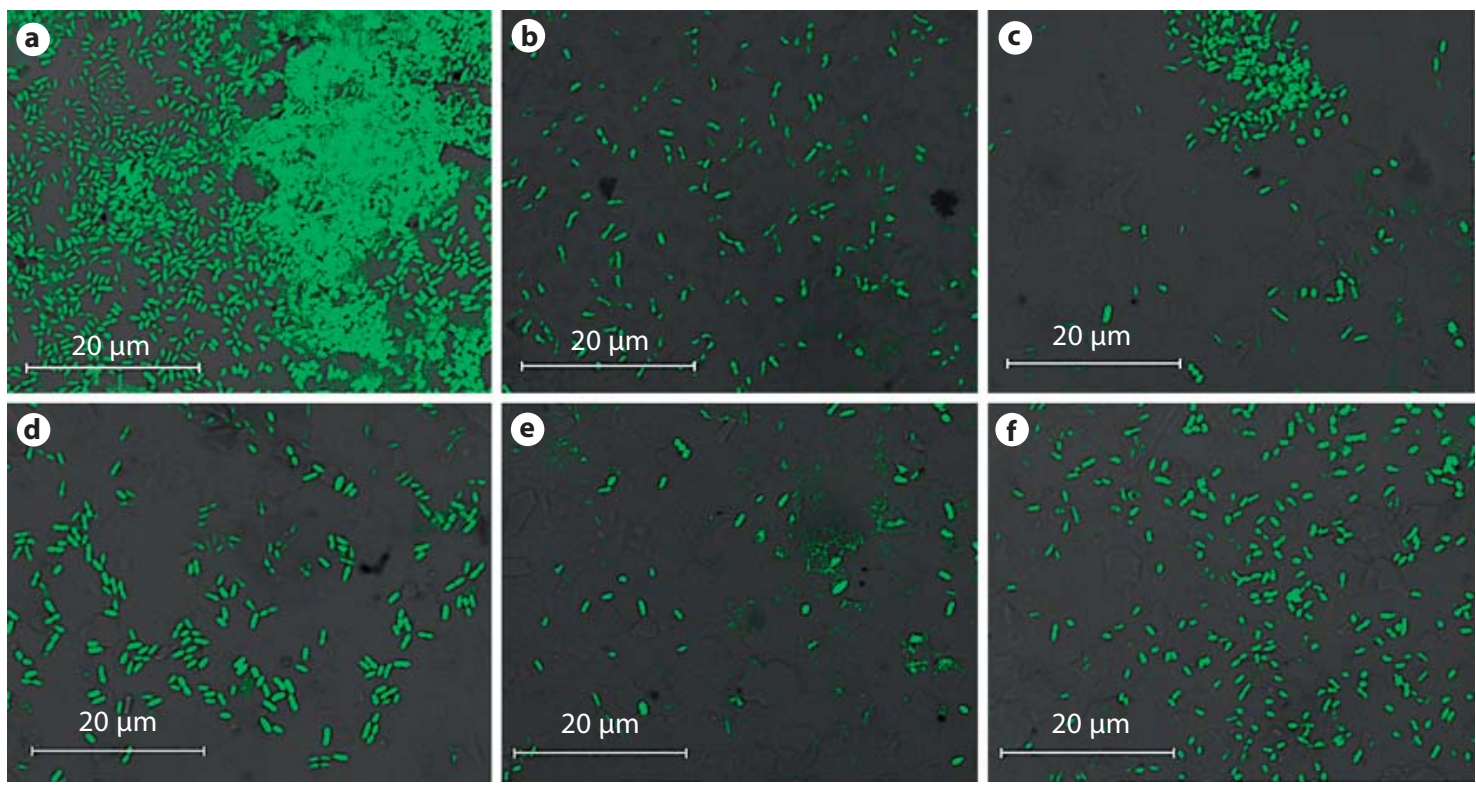

Fig. 2. Effect of antiseptics and TTP against biofilms. a Control in PBS. b CHX 0.1\%. c PHMB 0.02\%. d PHMB 0.04\%. e TTP. f Argon (gas control). Bacteria stained with acridine orange.

\section{Results}

\section{GV Assay}

For the microtitre plates, the results of the extinction measurement of the samples stained with GV showed no significant differences between the treatments (Friedman test, $\mathrm{p}=0.702$ ) (table 1 ). On the silicone test objects, the treatment with antiseptics likewise led to no significant effect (table 2). Negative values are explained by the subtraction of the control values. In contrast, plasma and gas led to a significant increase in the extinction compared with control and CHX (table 2).

\section{XTT Assay}

The converted amount of XTT stain as a measure of the metabolic activity of the microorganisms in the biofilm was significantly reduced by the antiseptics in the microtitre plate, while plasma and gas did not lead to a significant reduction (table 1). On the silicone test objects, only $0.04 \%$ PHMB led to a significant reduction compared to the control, while, as in the microtitre plate, plasma and gas led to an increase in the extinction that differed significantly from CHX and PBS (table 2).

\section{Colony-Forming Units}

The antimicrobial effect of the antiseptics and of the plasma was seen most clearly in the reduction of the CFU.
Both in the microtitre plates and on the silicone test objects the treatments (with the exception of $0.02 \%$ PHMB in the microtitre plate) led to a significant reduction in the CFU compared with the control, although there were no significant differences between the treatments. Only the plasma control gas on silicone and $0.02 \%$ PHMB in the microtitre plate were poorer than $\mathrm{CHX}$ (tables 1 and 2).

\section{Fluorochroming}

Acridine orange intensely fluoresces after intercalating with the DNA/RNA in living and dead bacteria. Compared to the untreated sample, the number of microorganisms in the preparation stained with acridine orange is clearly reduced (fig. 2). The clearest effects were seen for $0.1 \%$ CHX, TTP and 0.04\% PHMB. The live/ dead-stained preparation permits additional information about the vitality of the microorganisms in the biofilm (fig. 3). The dense, vital 'massive microorganism growth' in the control is killed by the antimicrobial treatments and reduced in its density. Live/dead-staining included the fluorochromes Syto9 and propidium iodide, both intercalating the DNA. Worth noting are the differences between gas and TTP on the one hand and between 0.02 and $0.04 \% \mathrm{PHMB}$ on the other. Both with TTP and with $0.04 \%$ PHMB, hardly any vital microorganisms stain after treatment. This is in conformity with the preparations 

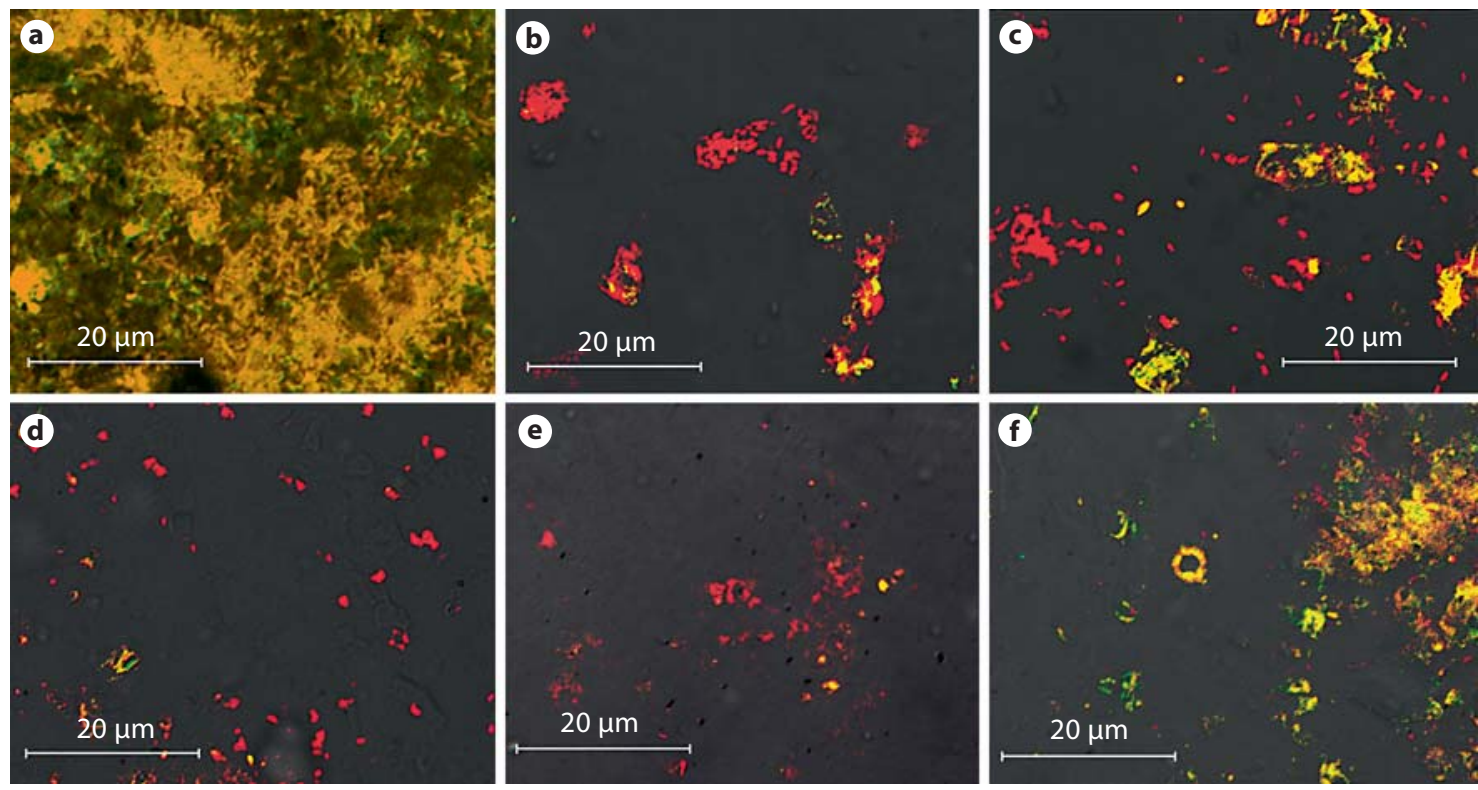

Fig. 3. Effect of antiseptics and TTP on biofilms grown in microtitre plates. a Control in PBS. b CHX $0.1 \%$. c PHMB 0.02\%. d PHMB 0.04\%. e TTP. f Argon (gas control). Bacteria stained fluorescent green (Syto9) have intact membranes, whereas bacteria stained red (propidium iodide) have damaged membranes, allowing propidium iodide to enter the cell. The micrographs show both the green and red channel, yellow locations represent areas where dyes overlapped.

stained with acridine orange, after which TTP and the higher PHMB concentration even inactivate 'islands', i.e. areas of high microorganism density.

\section{Discussion}

Biofilms make treatment of microbial infections more difficult. This applies especially if abiotic foreign bodies are present in the wound and form a basis for biofilm formation that is difficult for the immune system to access [1]. For accessibility to microbial biofilms, topical treatment with antiseptic measures is superior to the chemotherapeutic use of antibiotics, and in view of the increasing microbial resistance to antibiotics, it is of particular significance. In the study described here, the effects of PHMB and TTP in vitro in the presence of artificial wound fluid were compared with that of chlorhexidine as a substance with a proven effect against biofilms and seen as the gold standard to eliminate dental plaque [28-31]. However, it must be remembered that, depending on the test system, chlorhexidine also proved to be ineffective against biofilms [9]. The effectiveness of PHMB against biofilms was also shown [2, 32-34]. First investigations on the antimicrobial abilities of physical plasma against bacteria in biofilms have been published [35-37]. In the present study, the biofilms were cultured not only on routinely used microtitre plates, but also on silicone as a material frequently used in medicine with organic burden.

The results show that $\mathrm{PHMB}$ is comparable to $\mathrm{CHX}$ in its effect against the $P$. aeruginosa biofilm, irrespective of the material. In addition to efficacy, local tolerability and systemic toxicity play a decisive role for clinical use. PHMB has proved to be well tolerable and tissue-friendly [38], and in these respects is clearly superior to CHX [see Hübner and Kramer, this supplement issue]. On account of the deficient data situation on the clinical efficacy of CHX for wound treatment [39] and its tissue toxicity [11], in Germany CHX-based wound antiseptics are no longer authorized. The results in the biofilm model substantiate the results of clinical studies in which the potential of PHMB and products containing PHMB for the treatment of infected wounds could be demonstrated $[14,40-42]$.

TTP is a physical alternative to chemical antisepsis. In recent years, plasma sources for wound treatment have been developed and tested at several centres [43-46]. Two 
advantages of physical procedures are the fact that they can be standardized and the absence of entry of the antiseptic into the wound. In our tests, the microbicidal effect of plasma was comparable to that of $\mathrm{CHX}$, whereas the simple gassing with argon proved to be significantly poorer than CHX. This confirms that the antimicrobial effect is not just a result of drying by the gas current, but truly of the plasma itself. These reductions through TTP were not only statistically significant, but with $>3 \log _{10}$ correspond to the required efficacy for antiseptics [47]. This confirms the results of other authors reporting on the antimicrobial effects of TTP $[36,48]$.

However, the results regarding the determination of the biofilm mass could only be evaluated for the microtitre plates, as the drying caused by the flow of gas apparently altered the stainability on silicone.

To ensure the reproducibility of the results, standard methods of biofilm research were used. For the method of analysis of the solid substance, GV was used. This method is applied in many variations, which all follow the same scheme $[22,23]$. In contrast, the XTT test was modified with regard to the combination with menadione and $\mathrm{N}$-methylphenazinium methyl sulphate [25-27], because in the results of our previous studies in the case of $P$. aeruginosa the most intensive conversion of XTT was measured with this combination (data not shown). Nevertheless, the study has numerous limitations that must be taken into consideration in the evaluation. Evaluation of the metabolic activity by means of XTT must be made with caution for microorganism counts $<10^{5} \mathrm{CFU} /$ $\mathrm{ml}$ on account of the $\mathrm{S}$-shaped calibration curve for the stain. This particularly applies for the values for TTP and gas in the microtitre plate. To make the test conditions as similar as possible to the conditions in vivo, all tests were carried out in the presence of artificial wound fluid. However, this makes comparison with the results of other authors more difficult, as in the absence of such a load greater reductions tend to be achieved. With microtitre plates (polystyrene) and silicone, the choice of samples involved two materials that are frequently used in biofilm research. The results show that the results cannot be extrapolated uncritically to other materials, as just the two materials studied showed clear differences. The same applies for the plasma source used, as other configurations, especially changes in gas flow, energy density and type of plasma produced can lead to other results. Further investigations are therefore necessary in order to verify the efficacy for other microorganisms and under other conditions.

\section{Conclusion}

Biofilms play a key role in the pathogenesis of many acute and subacute microbial infections, including chronic wound and foreign-body-related infections. CHX and PHMB have been shown to be effective against bacteria in biofilms and could therefore be an interesting option for biofilm treatment. Topical antimicrobial therapy with TTP was also shown to be effective against $P$. aeruginosa biofilms on polystyrene and silicone materials. Further research should be done to evaluate the possible role of physical therapies for biofilm-derived infections.

\section{Acknowledgements}

The authors thank Prof. Hans-Curt Flemming for providing the SG 81 strain and Claudia Rändler and Jacqueline Menz for their help to perform the study.

\section{Disclosure Statement}

The authors declare that they have no stocks or stocks options related to any company manufacturing commercially available products on the basis of polihexanide as ingredient. Prof. Axel Kramer and Dr. Gerald Müller have a patent pending for a medical device that utilizes polihexanide as active agent. Prof. Axel Kramer and Dr. Nils-Olaf Hübner received consulting fees from B. Braun. Prof. Axel Kramer received financial support as a clinical investigator for B. Braun, Lohmann \& Rauscher, SeragWiesner and Fresenius. Dr. Nils-Olaf Hübner received financial support as a clinical investigator for B. Braun and Serag-Wiesner as well as speaker's honoraria for public medical education related to clinical use of antiseptics, including polihexanide. Dr. Gerald Müller received financial support for research from B. Braun, Lohmann \& Rauscher, Serag-Wiesner and Fresenius. All other authors declare no conflict of interest.

References

Skin Pharmacol Physiol 2010;23(suppl 1):28-34 biofilm-associated bacterial infections. Clin Pharmacol Ther 2007;82:204-209.

2 Seipp H, Hofmann S, Hack A, Skowronsky A, Hauri A: Efficacy of various wound irrigation solutions against biofilms. ZfW 2005: 160-164.

- 3 Fux CA, Costerton JW, Stewart PS, Stoodley P: Survival strategies of infectious biofilms. Trends Microbiol 2005;13:34-40.

4 Lewis K: Multidrug tolerance of biofilms and persister cells. Curr Top Microbiol Immunol 2008;322:107-131.

5 Stewart PS, Costerton JW: Antibiotic resistance of bacteria in biofilms. Lancet 2001;
Pozo JL, Patel R: The challenge of treating 358:135-138 
6 Pusateri CR, Monaco EA, Edgerton M: Sensitivity of Candida albicans biofilm cells grown on denture acrylic to antifungal proteins and chlorhexidine. Arch Oral Biol 2009;54:588-594.

-7 Karpanen TJ, Worthington T, Hendry ER, Conway BR, Lambert PA: Antimicrobial efficacy of chlorhexidine digluconate alone and in combination with eucalyptus oil, tea tree oil and thymol against planktonic and biofilm cultures of Staphylococcus epidermidis. J Antimicrob Chemother 2008;62:1031-1036.

8 Houari A, Di Martino P: Effect of chlorhexidine and benzalkonium chloride on bacterial biofilm formation. Lett Appl Microbiol 2007;45:652-656.

-9 Vitkov L, Hermann A, Krautgartner WD, Herrmann M, Fuchs K, Klappacher M, Hannig M: Chlorhexidine-induced ultrastructural alterations in oral biofilm. Microsc Res Tech 2005;68:85-89.

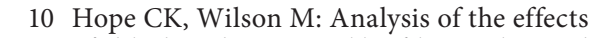
of chlorhexidine on oral biofilm vitality and structure based on viability profiling and an indicator of membrane integrity. J Antimicrob Chemother 2004;48:1461-1468.

-11 Müller G, Kramer A: Biocompatibility index of antiseptic agents by parallel assessment of antimicrobial activity and cellular cytotoxicity. J Antimicrob Chemother 2008;61: 1281-1287.

12 Horrocks A: Prontosan wound irrigation and gel: management of chronic wounds. $\mathrm{Br}$ J Nurs 2006;15:1222, 1224-1228.

13 Möller A, Kaehn K, Nolte A: Erfahrungen mit dem Einsatz polihexanidhaltiger Wundprodukte bei der Versorgung chronischer Wunden - Ergebnisse einer systematischen retrospektiven Untersuchung an 953 Patienten. Wundmanagement 2008;3:64-69.

14 Valenzuela AR, Perucho NS: The effectiveness of a $0.1 \%$ polyhexanide gel. Rev Enferm 2008;31:7-12.

-15 Sladek REJ, Stoffels E: Deactivation of Escherichia coli by the plasma needle. J Phys D Appl Phys 2005;11:1716.

-16 Von Woedtke T, Kramer A, Weltmann K-D: Plasma sterilization: what are the conditions to meet this claim? Plasma Process Polym 2008;5:534-539.

17 Kalghatgi SU, Fridman G, Fridman A, Friedman G, Clyne AM: Non-thermal dielectric barrier discharge plasma treatment of endothelial cells. Conf Proc IEEE Eng Med Biol Soc 2008;2008:3578-3581.

18 Grobe S, Fiedler S, Wingender J, Overath H: Wirkung von Chlor und Wasserstoffperoxid auf schleimbildende Bakterien aus wasserführenden Systemen. Vom Wasser 1994;83: 17.

19 Grobe S, Wingender J, Truper HG: Characterization of mucoid Pseudomonas aeruginosa strains isolated from technical water systems. J Appl Bacteriol 1995;79:94-102.

20 Weltmann K-D, Brandenburg R, Woedtke Tv, Ehlbeck J, Foest R, Stieber M, Kindel E: Antimicrobial treatment of heat sensitive products by miniaturized atmospheric pressure plasma jets (APPJs). J Phys D Appl Phys 2008;41:194008.
Foest R, Kindel E, Ohl A, Stieber M, Weltmann K-D: Non-thermal atmospheric pressure discharges for surface modification. Plasma Phys Control Fusion 2005;47:B525.

-22 Peeters E, Nelis HJ, Coenye T: Comparison of multiple methods for quantification of microbial biofilms grown in microtiter plates. Microbiol Methods 2008;72:157-165.

23 Vesterlund S, Paltta J, Karp M, Ouwehand AC: Measurement of bacterial adhesion - in vitro evaluation of different methods. Microbiol Methods 2005;60:225-233.

24 Mathur T, Singhal S, Khan S, Upadhyay DJ, Fatma T, Rattan A: Detection of biofilm formation among the clinical isolates of Staphylococci: an evaluation of three different screening methods. Indian J Med Microbiol 2006;24:25-29.

25 Thein ZM, Samaranayake YH, Samaranayake LP: In vitro biofilm formation of Candida albicans and non-albicans Candida species under dynamic and anaerobic conditions. Arch Oral Biol 2007;52:761-767.

26 Cerca N, Martins S, Cerca F, Jefferson KK, Pier GB, Oliveira R, Azeredo J: Comparative assessment of antibiotic susceptibility of coagulase-negative staphylococci in biofilm versus planktonic culture as assessed by bacterial enumeration or rapid XTT colorimetry. J Antimicrob Chemother 2005;56:331-336.

27 Sousa C, Teixeira P, Oliveira R: The role of extracellular polymers on Staphylococcus epidermidis biofilm biomass and metabolic activity. J Basic Microbiol 2009;49:363-370.

28 Zelic O, Cakic S, Lukovic N: The effect of two different oral antiseptics on dental plaque formation (de novo biofilm) and on gingival inflammation. Srp Arh Celok Lek 2009;137:6-9.

29 Lamfon H, Porter SR, McCullough M, Pratten J: Susceptibility of Candida albicans biofilms grown in a constant depth film fermentor to chlorhexidine, fluconazole and miconazole: a longitudinal study. J Antibicrob Chemother 2004;53:383-385.

30 Wirthlin MR, Chen PK, Hoover CI: A laboratory model biofilm fermenter: design and initial trial on a single species biofilm. J Periodontol 2005;76:1443-1449.

- 31 Auschill TM, Hein N, Hellwig E, Follo M, Sculean A, Arweiler NB: Effect of two antimicrobial agents on early in situ biofilm formation. J Clin Periodontol 2005;32:147-152.

32 Harbs N, Siebert J: In vitro efficacy of octenidine and polihexanide against biofilms composed of Pseudomonas aeruginosa. GMS Krankenhaushyg Interdiszip 2007; 2:Doc45(20071228).

33 Pietsch M, Kraft B: Antimikrobielle Wirksamkeit ausgewählter Substanzen für die Wasserdesinfektion in Dentaleinheiten mit Biofilm. Aseptica 2006;12:3-4.

34 Brecx M, Decker EM, Freitag HP, Maier G, Von Ohle C: The effect of polihexanide on dental biofilm formation in vivo. Conf Pan Eur Fed Int Assoc Dent Res, London, 2008.

35 Joaquin JC, Kwan C, Abramzon N, Vandervoort $\mathrm{K}$, Brelles-Marino $\mathrm{G}$ : Is gas-discharge plasma a new solution to the old problem of biofilm inactivation? Microbiology 2009; 155:724-732.
6 Abramzon N, Joaquin JC, Bray J, Brelles-Marino G: Biofilm destruction by RF high-pressure cold plasma jet. IEEE Trans Plasma Sci IEEE Nucl Plasma Sci Soc 2006;34:13041309.

37 Sladek RE, Filoche SK, Sissons CH, Stoffels E: Treatment of Streptococcus mutans biofilms with a nonthermal atmospheric plasma. Lett Appl Microbiol 2007;45:318-323.

38 Hirsch T, Koerber A, Jacobsen F, Dissemond J, Steinau HU, Gatermann S, Al-Benna S, Kesting M, Seipp HM, Steinstraesser L: Evaluation of toxic side effects of clinically used skin antiseptics in vitro. J Surg Res, E-pub ahead of print.

39 Cooper R: A review of the evidence for the use of topical antimicrobial agents in wound care. 2004. www.worldwidewounds. com/2004/february/Cooper/Topical-Antimicrobial-Agents.html.

40 Schmit-Neuerburg K, Bettag C, Schlickewei W, Fabry W, Hanke J, Renzig-Köhler K, Kirche H, Kock HJ: Wirksamkeit eines neuartigen Antisepticum in der Behandlung kontaminierter Weichteilwunden. Chirurg 2001;72:61-71.

41 Daeschlein G, Assadian O, Bruck JC, Meinl C, Kramer A, Koch S: Feasibility and clinical applicability of polihexanide for treatment of second-degree burn wounds. Skin Pharmacol Physiol 2007;20:292-296.

42 Roth B, Assadian O, Wurmitzer F, Kramer A: Surgical site infections after primary antiseptic cleansing of dirty-contaminated wounds by polihexanide, PVP iodine resp hydrogen peroxide. GMS Krankenhaushyg Interdiszip 2007;2:Doc58(20071228).

43 Stoffels E, Kieft IE, Sladek REJ, van der Bedem LJM, van der Laan EP, Steinbuch M: Plasma needle for in vivo medical treatment: recent developments and perspectives. Plasma Sources Sci Technol 2006;4:169.

- 44 Fridman G, Peddinghaus M, Balasubramanian $M$, Ayan $H$, Fridman A, Gutsol A, Brooks A: Blood coagulation and living tissue sterilization by floating-electrode dielectric barrier discharge in air. Plasma Chem Plasma Process 2006;16:425-442.

45 Watts AE, Fubini SL, Vernier-Singer M, Golkowski C, Shin S, Todhunter RJ: In vitro analysis of nonthermal plasma as a disinfecting agent. Am J Vet Res 2006;67:2030-2035.

46 Tipa RS, Stoffels E: Effects of Plasma Treatment on Wounds. 13th International Conference on Biomedical Engineering, IFMBE Proceedings. Berlin, Springer, 2009, pp 1385-1388.

- 47 Pitten FA, Werner HP, Kramer A: A standardized test to assess the impact of different organic challenges on the antimicrobial activity of antiseptics. J Hosp Infect 2003;55:108-115.

48 Chunqi J, Meng-Tse C, Amita G, Christoph S, David EJ, Costerton JW, Sedghizadeh PP, Vernier TP, Gundersen MA: Nanosecond pulsed plasma dental probe. Plasma Process Polym 2009;6:479-483. 